\title{
Selection of landmarks and semilandmarks in fishes for geometric morphometric analyses: a comparative study based on analytical methods
}

\author{
Marc Farré, Víctor M. Tuset, Francesc Maynou, Laura Recasens, Antoni Lombarte \\ Institut de Ciències del Mar, CSIC, Passeig Marítim de la Barceloneta 37-49, 08003, Barcelona, Catalonia, Spain. \\ E-mail: farre@icm.csic.es
}

\begin{abstract}
Summary: We applied and compared three different sets of landmarks and semilandmarks commonly used in studies of fish assemblages to identify a standardized method of landmark selection that includes the maximum amount of morphological information of species. The different landmark-based methods used produced differences regarding the distribution of casestudy species within the morphospace. We suggest that adding landmarks and semilandmarks that provide more specific information about anatomical structures with important roles in the biology of species, such as transformed fins or sensory organs, contributes to a clearer differentiation of species within the morphospace and a better interpretation of their occupancy. In addition, three types of method were used to establish how species are distributed within morphospace. The results demonstrated that aggregation points methods, including analyses based on quadrants or distances, are more appropriate for this purpose than indices of morphological disparity. The results also confirmed that although numerical methods are needed to test the statistical significance of outcomes, graphical methods provide a more intuitive interpretation of morphospace occupancy. The kernel density and Gabriel graph were useful to infer the morphospace zone where species are more densely grouped, improving the knowledge of space occupancy and structural complexity of fish assemblages.
\end{abstract}

Keywords: morphological traits; landmarks; geometric morphometrics; diversity; point pattern; morphospace; marine fishes.

Selección de puntos homólogos (landmarks) y equidistantes (semilandmarks) en peces para análisis de morfometría geométrica: un estudio comparativo basado en métodos analíticos

Resumen: En el presente estudio se compara la estructura de una comunidad de peces a partir del análisis morfológico de puntos homólogos (landmarks) y equidistantes (semilandmarks) en las especies de dicha comunidad. Para este propósito, se utilizaron tres metodologías distintas descritas en la literatura a la hora de definir dichos puntos con el fin de identificar cuál de ellas incluía la máxima cantidad de información morfológica posible sobre las especies. Las tres opciones proporcionaron diferentes resultados en relación a la distribución de las especies dentro del morfoespacio. Los resultados sugirieron que la incorporación de puntos que proporcionen información más específica sobre estructuras anatómicas que tienen papeles importantes en la biología de las especies, como aletas modificadas u órganos sensoriales, contribuye a una diferenciación más clara de las especies y a una mejor interpretación de la ocupación del morfoespacio. Adicionalmente, varios métodos numéricos y gráficos se emplearon con el fin de establecer cómo las especies se distribuyen dentro del morfoespacio. Los resultados demostraron que los métodos de agregación de puntos, incluyendo análisis basados en cuadrantes o distancias, fueron más apropiados para este propósito que los índices de disparidad morfológica. Además, los resultados también confirmaron que aunque los métodos numéricos fueron necesarios para evaluar la significancia estadística de los mismos, los métodos gráficos proporcionaron una interpretación más intuitiva y clara de la distribución de las especies dentro del morfoespacio. La densidad de Kernel y los gráficos de Gabriel se mostraron muy útiles a la hora de deducir la zona del morfoespacio donde las especies estaban más densamente agrupadas, hecho que ayudó a mejorar el conocimiento de la ocupación del espacio y de la complejidad estructural en comunidades de peces.

Palabras clave: características morfológicas; puntos homólogos; morfometría geométrica; diversidad; patrón de puntos; morfoespacio; peces marinos.

Citation/Como citar este artículo: Farré M., Tuset V.M., Maynou F., Recasens L., Lombarte A. 2016. Selection of landmarks and semilandmarks in fishes for geometric morphometric analyses: a comparative study based on analytical methods. Sci. Mar. 80(2): 175-186. doi: http://dx.doi.org/10.3989/scimar.04280.15A

Editor: A. Garcia-Rubies.

Received: June 4, 2015. Accepted: February 26, 2016. Published: May 17, 2016.

Copyright: () 2016 CSIC. This is an open-access article distributed under the Creative Commons Attribution-Non Commercial Lisence (by-nc) Spain 3.0. 


\section{INTRODUCTION}

The use of morphology emerged as a scientific discipline in the early 20th century based on the 'form, shape, and function' of species morphologies (Thompson 1915, Russell 1916). From then until now, this approach has been applied in many studies and has been suggested as a useful tool for better understanding the mechanisms promoting species coexistence, for inferring the ecological strategies of species (e.g. Gatz 1979, Bellwood et al. 2006) and for investigating fluctuations within a community due to natural or anthropogenic perturbations (Villéger et al. 2010, Korn et al. 2013). Initially, changes in shape of species were assessed from linear measurements (Strauss and Bookstein 1982, Winemiller 1991, Klingenberg and Ekau 1996). In the 1990s, a new approach, called geometric morphometrics, allowed analyzing shape variation and its covariation (Bookstein 1991, Rohlf and Marcus 1993, Adams et al. 2013). These methods quantify the shape variation of objects from the Cartesian coordinates of anatomical landmarks, unifying a rigorous statistical theory with analytical procedures for superimposing landmark configurations of all specimens in a common coordinate system. Therefore, in addition to dealing with issues related to allometry and isometry, the power of this method lies in the ability to detect and visualize shape differences more clearly than classical approaches (Clabaut et al. 2007, Adams et al. 2013).

In landmark-based studies, a common "conflict" arises in the definition of the number and position of the homologous landmarks between organisms (Cadrin 2000, Klingenberg 2010, Smith and Hendricks 2013). This is an important setback because the use of different criteria to define landmarks can influence results (Klingenberg 2010, Van Bocxlaer and Schultheiß 2010, Adams et al. 2013). In fishes, most landmark sets have mainly focused on feeding and locomotion apparatus, which are considered the primary drivers of coexistence and specific richness (e.g. Winemiller 1991, Wainwright et al. 2002, Cooper and Westneat 2009), and on body shape, which is a multitasking factor contributing to multiple traits, such as swimming, food capture, evading predators, courtship, defending territories and spawning (e.g. Valentin et al. 2002, Costa and Cataudella 2007, Walker 2010). Other anatomical parts, such as pelvic and pectoral fins or sensorial organs (barbels or illicia), are not usually included because they are not rigid structures and are difficult to preserve intact, and it is often difficult to define homologous positions of these structures between species (Bookstein 1991, Chakrabarty 2005). However, it has been demonstrated that these structures are key factors in many fish behaviours (Yamanoue et al. 2010), such as movement and body position (Zuanon et al. 2006), prey capture (Laurenson et al. 2004) and receiving chemical stimuli (Kasumyan 2011), so they are important in the functional and ecological role of species within communities. Although many researchers currently question their use in landmark methods, claiming that they are not solid structures, that they have highly variable positions that are difficult to standardize, or even that some of them are absent (Chakrabarty 2005), fins have been applied in evolutionary (Friedman 2010, Dornburg et al. 2011), phylogenetic (Vergara-Solana et al. 2014), ecological (Wainwright et al. 2002, Lombarte et al. 2012, Farré et al. 2015) and biodiversity studies (Farré et al. 2013).

Morphological variations between organisms can be plotted in a morphospace where the species distribution and occupied space provide useful information on the structural complexity of the community (McClain et al. 2004, Clabaut et al. 2007). There are three main approaches for exploring the distribution of points within space: indices of morphological disparity, quadrant analyses (based on density of points), and nearestneighbour analyses (based on distance between points and their association), which can be represented in numerical measurements or graphical analysis (Ciampaglio et al. 2001, Zelditch et al. 2004, Werdelin and Lewis 2013). Numerical methods such as the morphological disparity (e.g. sum of range, sum of variance or position of centroid), the average link length of a minimum spanning tree, the average distance between any species and its nearest neighbour and participation ratio, do not provide the relative position of points in morphospace (Foote 1997, Ciampaglio et al. 2001, Zelditch et al. 2004). Nevertheless, it is possible to infer whether data follow random, uniform, or clustered spatial patterns (Pie and Traniello 2007).

By contrast, graphical approaches are alternative ways for improving the knowledge of the distribution of points. The convex hull is useful to detect species contributing to a greater extent to the diversity of morphospace (Cornwell et al. 2006, Werdelin and Lewis 2013). However, this approach is unable to assess the internal structure of morphospace (Shen et al. 2008, Tuset et al. 2014). The analysis of the distribution of points within morphospace is usually performed using the Euclidean minimum spanning tree, the relative neighbourhood graph, the nearest-neighbour graph, the Gabriel graph or kernel density, which display the main groupings of species and gaps where species are absent (Gabriel and Sokal 1969, Worton 1989; Dale and Fortin 2010). Similarly, Ripley's function infers on the spatial distribution pattern (random, uniform, or clustered) (Ripley 1979, Perry et al. 2006, Werdelin and Lewis 2013).

Our hypothesis was that the selection scheme of landmarks and semilandmarks can affect the morphospace configuration of fish assemblages. In addition, we wanted to determine the analytical methods that best describe the distribution and occupation of morphospaces. Therefore, the aims of the present study were (i) to apply, assess and compare different landmark and semilandmark schemes used in previous fish studies to discern the differences between the criteria and determine how the selection of landmarks influences the distribution patterns of fishes within the morphospace, and (ii) to analyse the internal structure of morphospaces using different analytical methods and then identify those that provide most complete information in order to explain the organization of fish species within the mosphospaces. 
Table 1. - List of species of the artificial reef-sandy assemblage analysed in this study (Calafell, Catalan coast, NW Mediterranean), taxonomical classification of the species (order and family) and the acronym used for each species.

\begin{tabular}{|c|c|c|c|}
\hline Order & Family & Specie & Acronym \\
\hline Anguilliformes & Congridae & Conger conger & Ccon \\
\hline Gadiformes & Merlucciidae & Merluccius merluccius & Mmer \\
\hline Gadiformes & Phycidae & Phycis phycis & Pphy \\
\hline Lophiiformes & Lophiidae & Lophius piscatorius & Lpis \\
\hline Mugiliformes & Mugilidae & Chelon labrosus & Clab \\
\hline Mugiliformes & Mugilidae & Liza aurata & Laur \\
\hline Mugiliformes & Mugilidae & Mugil cephalus & Mcep \\
\hline Mugiliformes & Mugilidae & Liza ramada & Lram \\
\hline Perciformes & Moronidae & Dicentrarchus labrax & Dlab \\
\hline Perciformes & Serranidae & Serranus cabrilla & Scab \\
\hline Perciformes & Carangidae & Seriola dumerili & Sdum \\
\hline Perciformes & Haemulidae & Pomadasys incisus & Pinc \\
\hline Perciformes & Sparidae & Boops boops & Bboo \\
\hline Perciformes & Sparidae & Dentex dentex & Dden \\
\hline Perciformes & Sparidae & Diplodus annularis & Dann \\
\hline Perciformes & Sparidae & Diplodus cervinus & Dcer \\
\hline Perciformes & Sparidae & Diplodus sargus & Dsar \\
\hline Perciformes & Sparidae & Diplodus vulgaris & Dvul \\
\hline Perciformes & Sparidae & Lithognathus mormyrus & Lmor \\
\hline Perciformes & Sparidae & Pagellus acarne & Paca \\
\hline Perciformes & Sparidae & Pagellus bogaraveo & Pbog \\
\hline Perciformes & Sparidae & Pagellus erythrinus & Pery \\
\hline Perciformes & Sparidae & Pagrus pagrus & Ppag \\
\hline Perciformes & Sparidae & Sparus aurata & Saur \\
\hline Perciformes & Sparidae & Spondyliosoma cantharus & Scan \\
\hline Perciformes & Sciaenidae & Sciaena umbra & Sumb \\
\hline Perciformes & Sciaenidae & Umbrina canariensis & Ucan \\
\hline Perciformes & Sciaenidae & Umbrina cirrosa & Ucir \\
\hline Perciformes & Mullidae & Mullus barbatus & Mbar \\
\hline Perciformes & Mullidae & Mullus surmuletus & Msur \\
\hline Perciformes & Pomacentridae & Chromis chromis & Cchr \\
\hline Perciformes & Labridae & Coris julis & Cjul \\
\hline Perciformes & Labridae & Labrus merula & Lmer \\
\hline Perciformes & Uranoscopidae & Uranoscopus scaber & Usca \\
\hline Pleuronectiformes & Scophthalmidae & Scophthalmus rhombus & Srho \\
\hline Pleuronectiformes & Scophthalmidae & Psetta maxima & Pmax \\
\hline Pleuronectiformes & Bothidae & Arnoglossus laterna & Alat \\
\hline Pleuronectiformes & Bothidae & Bothus podas & Bpod \\
\hline Pleuronectiformes & Citharidae & Citharus linguatula & Clin \\
\hline Pleuronectiformes & Soleidae & Microchirus variegatus & Mvar \\
\hline Pleuronectiformes & Soleidae & Solea lascaris & Slas \\
\hline Pleuronectiformes & Soleidae & Solea senegalensis & Ssen \\
\hline Pleuronectiformes & Soleidae & Solea solea & Ssol \\
\hline Pleuronectiformes & Soleidae & Synaptura lusitanica & Slus \\
\hline Scorpaeniformes & Scorpaenidae & Scorpaena notata & Snot \\
\hline Scorpaeniformes & Scorpaenidae & Scorpaena porcus & Spor \\
\hline Scorpaeniformes & Scorpaenidae & Scorpaena scrofa & Sscr \\
\hline Scorpaeniformes & Triglidae & Trigla lucerna & Tluc \\
\hline
\end{tabular}

\section{MATERIALS AND METHODS}

\section{Fish collection}

A fish database of a coastal assemblage of the Catalan Coast, northwestern Mediterranean $\left(40.5-42.5^{\circ} \mathrm{N}\right.$, $0.30-3.25^{\circ} \mathrm{E}$ ) was used for this study. In particular, an artificial reef-sandy assemblage of the central coast $\left(41^{\circ} 10.52^{\prime} \mathrm{N}, 1^{\circ} 35.16^{\prime} \mathrm{E}\right)$ was selected due to its high species richness, morphological richness and functional and taxonomical diversity (Farré et al. 2013). This artificial reef consists of a group of modules that were installed between 1987 and 1998 to avoid illegal trawling (Recasens et al. 2006). Fishes were collected bi-monthly by small-scale vessels with trammel nets in 2000-2003. The characteristics of trammel net fisheries in the study area are described in the literature (Recasens et al. 2006, Farré et al. 2013). For each fishing operation, the entire fish catch (commercial plus discarded fraction) was retained. A total of 48 species were identified (Mercader et al. 2001, Nelson 2006) (Table 1) and photographed (only one specimen per species). The photographic record of species was carried out using a standardized and homologous body position for all species (facing left), including fins and sensorial organs position and size, in order to avoid differences in the disposition of the anatomical structures between species that allow the application and comparison of different landmark-based methods in the morphological analyses (see Fig. 1).

\section{Building morphospaces}

Morphological diversity of fish shapes was quantified using geometric morphometric techniques (Bookstein 1991, Rohlf and Marcus 1993, Zelditch et al. 2004). The selection of landmarks and semilandmarks was based on commonly used choices in previous morphometric studies in fishes. Three different criteria considering all the recorded options in the bibliogra- 


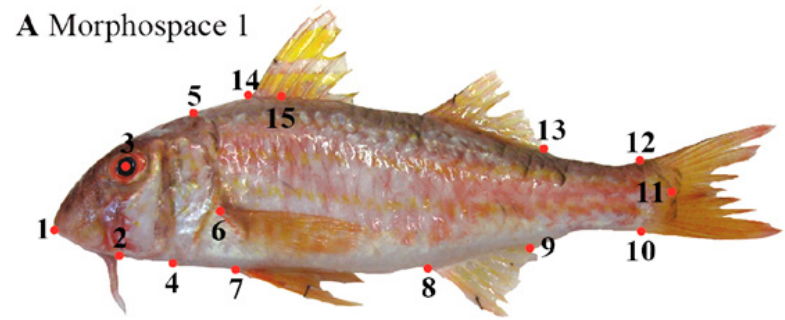

B Morphospace 2
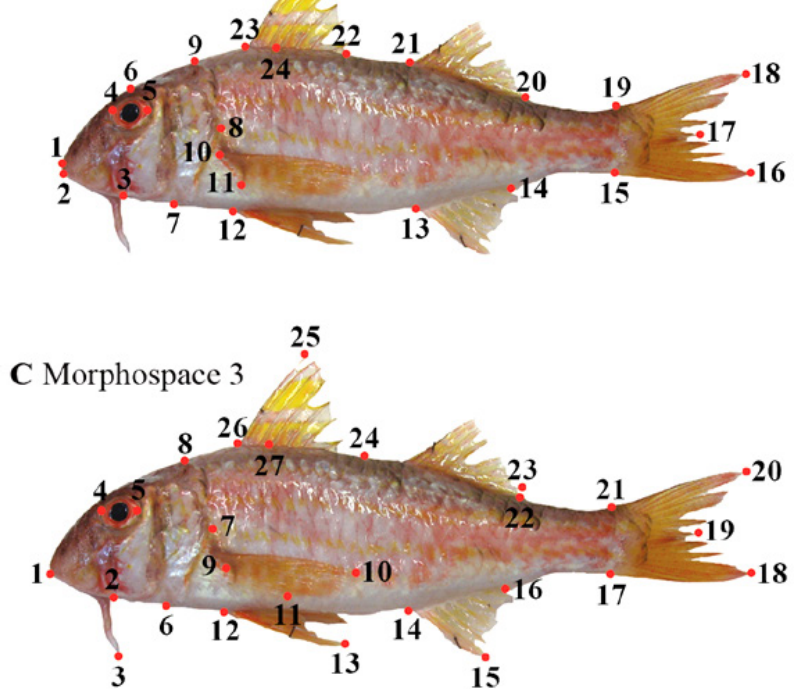

Fig. 1. - Location of the selected landmarks and semilandmarks on the left side of standardized images for the three different methods used (morphospace 1,2 and 3). The description of the meaning of landmarks for each method is detailed in Table 2. In method 1 (morphospace 1), landmark 15 is a semilandmark; in method 2 (morphospace 2), landmarks 16, 17, 18 and 24 are semilandmarks; and in method 3 (morphospace 3), landmarks 3, 10, 11, 13, 15, 18, 19 , $20,23,24,25$ and 27 are semilandmarks. The species in the images is Mullus surmuletus.

phy were used (a detailed description of the meaning of landmarks and semilandmarks for each method is provided in Table 2): first, defining basically the body and head shape, widely used and considered to best represent the external shape of the body morphology (Fig. 1A, morphospace 1) (Loy et al. 1999, Chakrabarty 2005, Costa and Cataudella 2007); second, adding the eye size and the position of fins and caudal fin shapes, traits often recorded in paleontological and evolutionary studies given their ecological and functional importance (Fig. 1B, morphospace 2) (Young et al. 2009, Friedman 2010); and third, a partial combination of the first two methods, including the shape, size and position of all fins and sensorial organs (Fig. 1C, morphospace 3) (Recasens et al. 2006, Farré et al. 2013, Azzurro et al. 2014).

We digitized the landmarks and semilandmarks in one standardized image of the left profile of species previously obtained as a consensus figure from different specimens using tpsDig v. 2.16 software (Rohlf 2003a) for geometric morphometric analysis. However, direct analysis of landmark coordinates contains other components unrelated to shape, such as position, orientation and size (Angeles et al. 2014). To remove these distortions, a generalized least-squares superimposition (GLS) procedure (generalized Procrustes) was applied, translating all specimens to a common centroid position in the coordinate system, scaling them to unit centroid size and rotating them to minimize the distances between corresponding landmarks (Kassam et al. 2003, Angeles et al. 2014). Thus, working on standardized consensus images, superimposition methods allow the analysis of morphology independently of size (Layman et al. 2005). However, GLS Procrustes coordinates are not expressed in $\mathrm{Eu}-$ clidean shape space. Therefore, these coordinates should be previously projected in a Euclidean tangent space in order to test whether the shape variation is small enough to consider that this new tangent space is a good representation of the Procrustes data in a Euclidean space (Dryden and Mardia 1998). Then, to check whether the variation between the two spaces was minimum for our communities, we computed the correlations between the tangent and Procrustes distances using tpsSmall v. 1.28 (Rohlf 2003b). The results of correlations (Morphospace 1: uncentred correlation $=0.999988$, root mean square error $=0.000419$; Morphospace 2: uncentred correlation $=0.999993$, root mean square error $=0.000404$; Morphospace 3: uncentred correlation $=0.999979$, root mean square error $=0.000639$ ) confirmed that for the three methodologies both spaces were nearly identical.

We then conducted a relative warp analysis of superimposed images using tpsRelw v. 1.49 (Rohlf 2003c). Each relative warp axis represents a set of specific morphological characteristics, allowing particular morphological attributes of species to be analysed directly (e.g. Rohlf and Marcus 1993, Zelditch et al. 2004, Layman et al. 2005). Morphospaces were built from relative warps 1,2 and 3 in order to capture the maximum and most important information about shape variation (Recasens et al. 2006). These first three relative warps attained $84.7 \%$ (morphospace 1), 81.7\% (morphospace 2) and 78.6\% (morphospace 3) of total morphological variability, considered a sufficiently representative percentage of the total amount of explained morphological variation. Finally, we reduced the three axes to two by applying a non-metric multidimensional scaling technique (nMDS) (Shen et al. 2008) to obtain a multidimensional graphical representation of the distribution of fish assemblages based on their similarity.

\section{Point pattern analyses}

Three types of descriptor were used to establish the spatial variability in the morphospaces: indices of morphological disparity, quadrant analyses and nearestneighbour analyses (a complete scheme of the different analyses performed is shown in Figure 2). The last two analyses included numerical and graphical methods.

Among the various disparity measures described in the literature (Ciampaglio et al. 2001, Wills 2001, Korn et al. 2013), the following two indices of morphological disparity were used: a) Sum of variance (SOV), which is the sum of the variances along all the morphospace axes; and b) Sum of range of the middle two quartiles (QSOR), which defines the area that is 
Table 2. - Description of the morphological meaning of the selected landmarks and semilandmarks for the three methods analysed. Landmark scheme of morphospace 1 based on Loy et al. 1999, Chakrabarty 2005 and Costa and Cataudella 2007; morphospace 2 based on Young et al. 2009 and Friedman 2010; and morphospace 3 based on Recasens et al. 2006, Farré et al. 2013 and Azzurro et al. 2014. In bold the exclusive landmarks of each morphospace; the remaining ones are homologous in all the morphospaces.

\begin{tabular}{ll}
\hline Landmarks & \multicolumn{1}{c}{ Morphospace 1 } \\
\hline 1 & Anterior tip of the mouth \\
2 & Posterior tip of the mouth \\
3 & $\begin{array}{l}\text { Central point in the midline through } \\
\text { the eye }\end{array}$
\end{tabular}

\section{Ventral margin in the end of the head}

Dorsal margin in the end of the head

Dorsal insertion of the pectoral fin

Insertion of the pelvic fin

Anterior insertion of the anal fin

Posterior insertion of the anal fin

Ventral insertion of the caudal fin

\section{Posterior margin of the caudal} peduncle

Dorsal insertion of the caudal fin

Posterior insertion of the dorsal fin (second dorsal fin if exists)

Anterior insertion of the dorsal fin (first dorsal fin if second fin exists)

Point of maximum body height in the body margin
Anterior margin in the maximum eye width

Posterior margin in the maximum eye width

Dorsal margin of the head exactly above the centre of the eye

Ventral margin in the end of the head

Posterior margin in the end of the head

Dorsal margin in the end of the head

Dorsal insertion of the pectoral fin

Ventral insertion of the pectoral fin

Insertion of the pelvic fin

Anterior insertion of the anal fin

Posterior insertion of the anal fin

Ventral insertion of the caudal fin

Distal tip of the ventral lobe of the caudal

fin when the fin is in position of maximum extension

Posterior margin of the caudal fin between dorsal and ventral lobes

Distal tip of the dorsal lobe of the caudal fin when the fin is in position of maximum extension

Dorsal insertion of the caudal fin

Posterior insertion of the dorsal fin ( $\mathrm{sec}$ ond dorsal fin if it exists) Morphospace 3

Anterior tip of the mouth

Posterior tip of the mouth

Distal tip of the barbel, placed at $80^{\circ}$ of the body margin (or projection in the lower jaw inferior margin of the position of the hyomandibular insertion, when no barbels)

Anterior margin in the maximum eye width

Posterior margin in the maximum eye width

Ventral margin in the end of the head

Posterior margin in the end of the head

Dorsal margin in the end of the head

Central point in the baseline of the pectoral fin

Posterior tip of the pectoral fin when

the fin is in position of maximum extension

Ventral margin of the pectoral fin when the fin is in position of maximum extension

Insertion of the pelvic fin

Distal tip of the pelvic fin when the fin is in position of maximum extension

Anterior insertion of the anal fin

Distal tip from the anterior insertion of the anal fin when the fin is in position of maximum extension

al Posterior insertion of the anal fin

Ventral insertion of the caudal fin

Distal tip of the ventral lobe of the caudal fin when the fin is in position of maximum extension

Posterior margin of the caudal fin between dorsal and ventral lobes

Distal tip of the dorsal lobe of the caudal fin when the fin is in position of maximum extension

Anterior insertion of the second dorsal Dorsal insertion of the caudal fin fin (if it exists)

Posterior insertion of the first dorsal fin (if second dorsal fin exists)

Posterior insertion of the dorsal fin (second dorsal fin if it exists)

Anterior insertion of the dorsal fin (first Posterior tip of the dorsal fin (second dorsal fin if second fin exists)

Point of maximum body height in the body margin dorsal fin if it exists) when the fin is in position of maximum extension

Transition point between spines and soft rays in the dorsal fin (if only one dorsal fin exists) or central point in the gap between the two dorsal fins on the dorsal margin of the body (if second dorsal fin exists)

Distal tip of the first spine of the dorsal fin (first dorsal fin if second fin exists) when the fin is in position of maximum extension

Anterior insertion of the dorsal fin (first dorsal fin if second fin exists)

Point of maximum body height in the body margin 


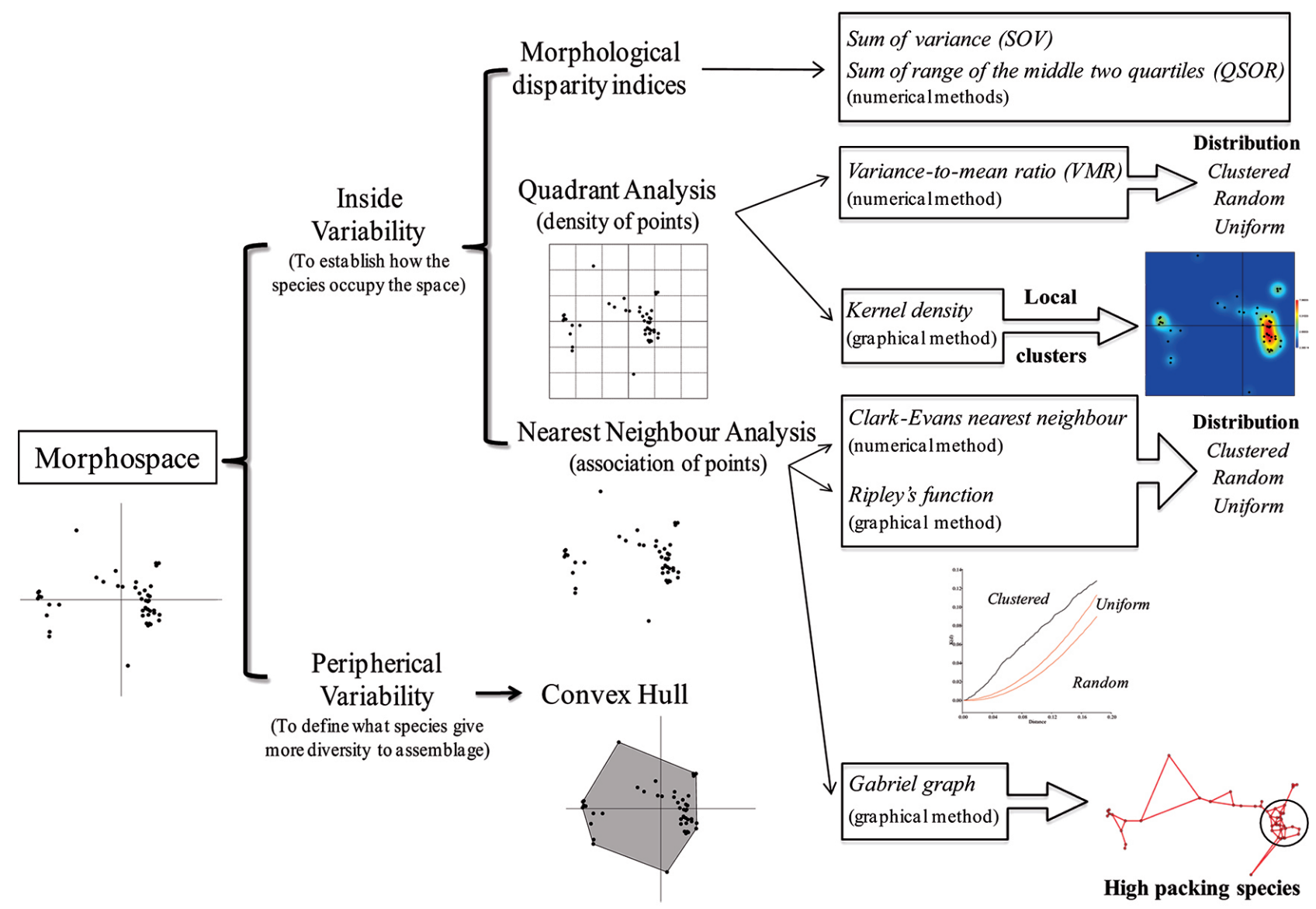

Fig. 2. - Explanatory scheme for the procedure of analysis of morphospaces, including all the analyses and methods used.

occupied by the middle two quartiles of the data points along the $\mathrm{x}$ and $\mathrm{y}$ axes, providing information about the distribution pattern of points within the morphospace.

In the quadrant analyses, it was estimated the variance-to-mean ratio (VRM), a numerical method which is defined as the ratio of variance to the mean:

$$
\mathrm{VRM}=\frac{\sigma^{2}}{\mu},
$$

when $\mathrm{VMR}>1$, it corresponds to a clustered distribution; when $\mathrm{VMR}<1$, it denotes an ordered distribution; and when $\mathrm{VMR} \approx 1$, the distribution is uniform or more exactly follows a Poisson random distribution. A Kolmogorov-Smirnov (K-S test) test was applied to compare the observed and expected frequencies derived from the Poisson frequency distribution (Anderson et al. 1982). Graphically, the kernel density was determined for the localization of clusters of species using a Gaussian function:

$$
f(x, y)=\frac{1}{2 \pi r^{2}} \sum_{i} e^{-\frac{d_{i}^{2}}{2 r^{2}}}
$$

where

$$
d_{i}=\sqrt{\left(x-x_{i}\right)^{2}+\left(y-y_{i}\right)^{2}},
$$

$x$ and $y$ are the coordinates of points, and $r$ is the radius (Worton 1989, Fortin et al. 2005, Werdelin and Lewis 2013).
For nearest-neighbour analyses, the numerical value of the Clark-Evans nearest neighbour was obtained to compare the average distance between nearest neighbours with the expected distance in the case of random distribution using the following equation:

$$
r=\frac{\text { mean distance }}{\frac{1}{2} \sqrt{\text { density }}}
$$

when $r<1$, points are clustered; when $r=1$, the points occur in a random distribution; and when $r>1$, the points are evenly dispersed (Davis 1986, Werdelin and Lewis 2013). The expected (theoretical) distribution under the null hypothesis is plotted as a continuous curve together with the histogram of observed distances. The expected probability density function as a function of distance $r$ is:

$$
g(r)=2 \rho \pi r e^{\left(-\rho \pi r^{2}\right)}
$$

where $\rho=n / A$ is the density, $n$ is number of points, and $A$ is the estimation area from the convex hull (Clark and Evans 1954, Cornwell et al. 2006). In addition, it was also estimated the Ripley function, a graphical method that is also related to the nearest-neighbour distribution function and incorporates local variations, defined as:

$$
\hat{K}(d)=\frac{1}{\lambda n} \sum_{i=1}^{n} \sum_{j \neq 1} I\left(d_{i j}<d\right)
$$


where $d_{\mathrm{ij}}$ is the Euclidean distance between the $i^{\text {th }}$ and $j^{\text {th }}$ points in a data set of $n$ points, and $\lambda$ is the average density of points (Ripley 1979, Dixon 2002, Perry et al. 2006). Finally, the localization of species clusters was obtained from the Gabriel graph, an undirected graph or betaskeleton expressing one notion of proximity or nearness among points allowing the localization of packings. The graph consists of two sets: nodes or points; and edges or lines, which represent connections between pairs of nodes showing which points are clumped (Gabriel and Sokal 1969, Dale and Fortin 2010).

Finally, another graphical method, the convex hull, was used to define which species contribute most to the morphological diversity of morphospaces, allowing us to determine the peripheral shape of morphospaces.

\section{RESULTS}

\section{Species distribution within the morphospace}

All the morphospaces showed a similar spatial variability in the species distribution, with matched
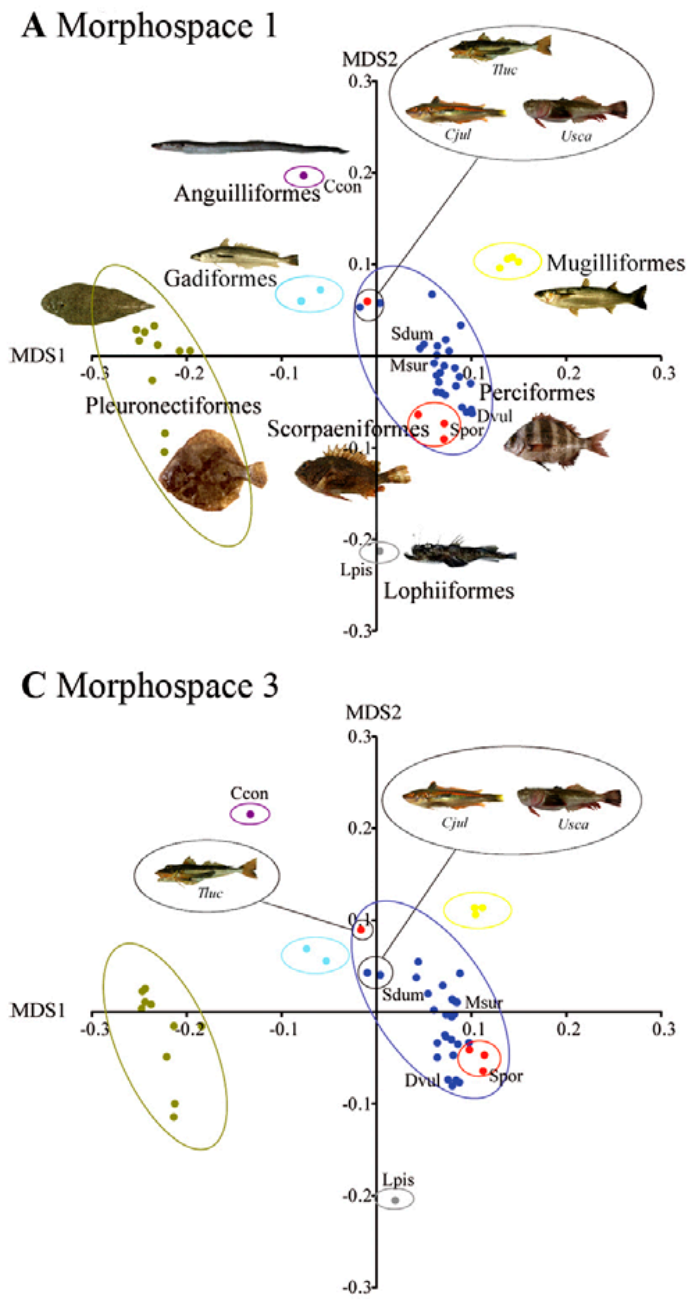

or very similar convex hull configurations (Fig. 3D). Morphospaces 1 and 3 presented no species close to the morphospace core. However, two species packs formed by Perciformes-Scorpaeniformes and Pleuronectiformes were located to the right and left side, respectively, while other different groups, including Anguilliformes, Gadiformes, Lophiiformes and $\mathrm{Mu}-$ giliformes, occupied their own isolated areas in the morphospace (Fig. 3A and 3C). Instead, morphospace 2 showed a different spatial organization that was more extended in the first axis, separating the fishes in relation to number and position of dorsal fins (Fig. 3B). Negative values mainly corresponded to species with a continuous dorsal fin along the body located in the anterior position; the morphospace core was occupied by benthic species with one shorter dorsal fin originating at the end of the head, as in some Perciformes (Labridae, Serranidae and Sparidae) and Scorpaeniformes; and positive values were associated with species with two dorsal fins, including a high variety of fishes, such as Gadiformes, Mugiliformes and some Perciformes (Scianidae, Mullidae or Carangidae) (Fig. 3B).

\section{B Morphospace 2}
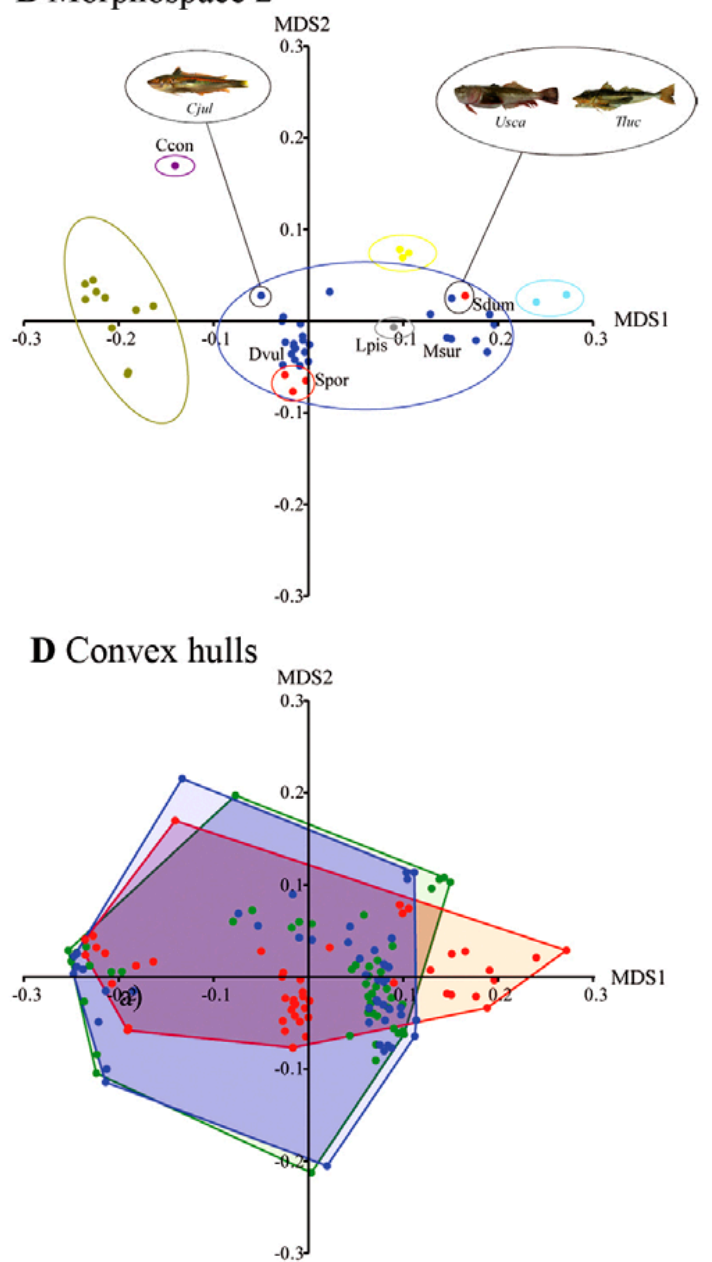

Fig. 3. - Representation of the morphospace for the first (A), second (B) and third method (C) showing the main differentiated groups of species. Ccon, Conger conger; Cjul, Coris julis; Dvul, Diplodus vulgaris; Lpis, Lophius piscatorius; Msur, Mullus surmuletus; Sdum, Seriola dumerili; Spor, Scorpaena porcus; Tluc, Trigla lucerna; Usca, Uranoscopus scaber. Colour legend of dots: Perciformes in dark blue, Scorpaeniformes in red, Pleuronectiformes in brown, Gadiformes in light blue, Mugiliformes in yellow, Lophiiformes in grey and Anguilliformes in purple. $\mathrm{D}$, superimposed representation of the convex hull structure of the morphospaces for the three methods analysed. Morphospace 1 in green, morphospace 2 in red and morphospace 3 in blue, $n=48$. 
A Kernel density
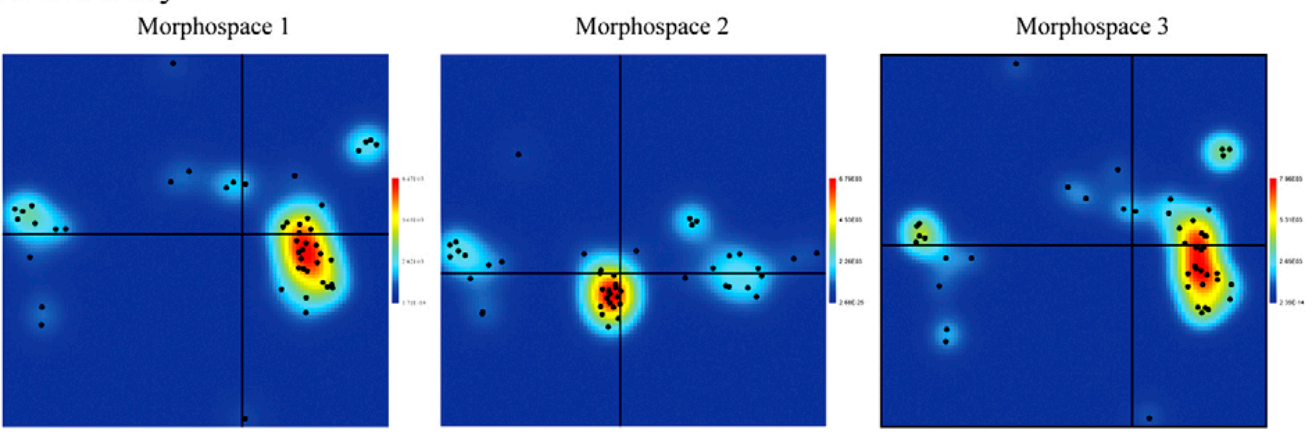

B Ripley function
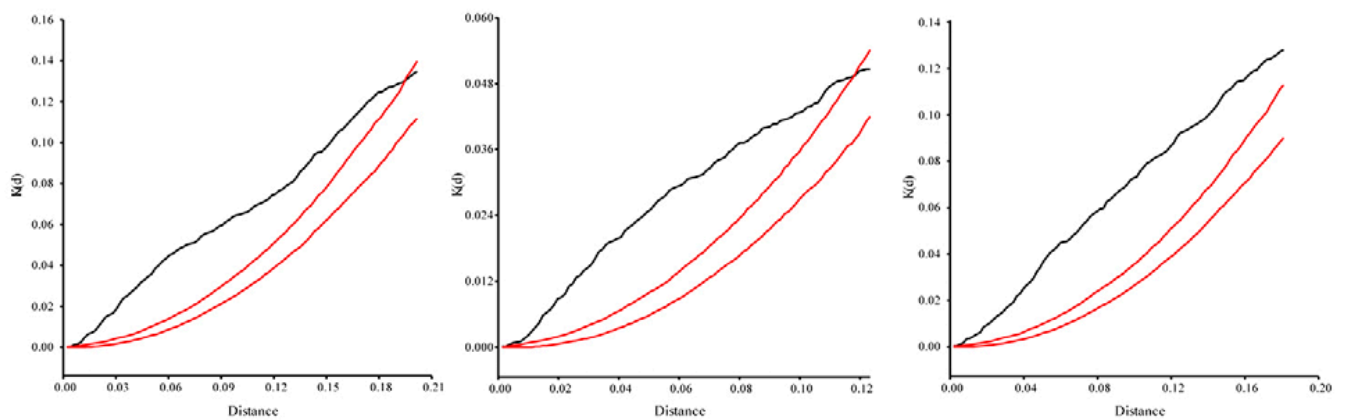

\section{Gabriels graphs}

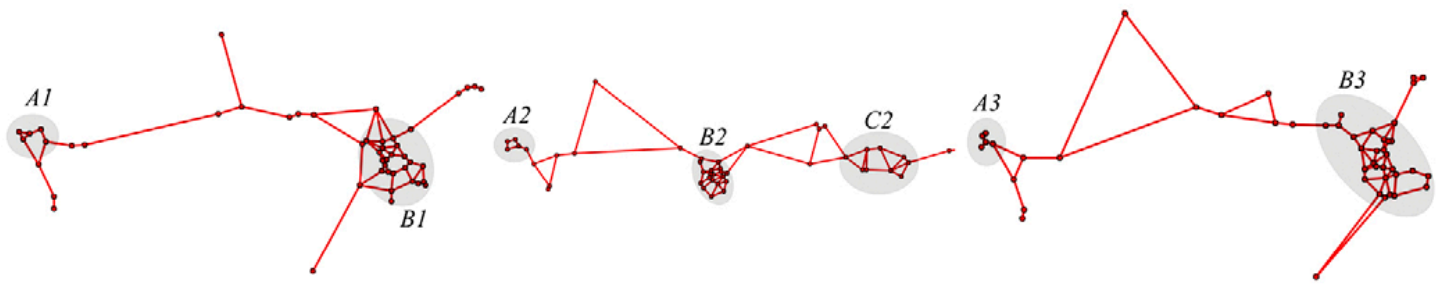

Fig. 4. - Representation of the kernel density (A), the graphic of the Ripley's function (B) and the Gabriel graphs (C) for the three methods analysed. In the kernel graphics, colour legend indicates the degree of density of species (maximum density in red, minimum density in dark blue). In the graph of the Ripley's function, the two red curves represent the 95\% confidence envelopes of the function; and the obtained curve is in black. In the Gabriel graphs, grey shading circles represent the main species packings, $n=48$.

The second axis mainly distinguished between elongated (positive values) or rounded (negative values) body shapes in all of the morphospaces (Fig. 3A and $3 \mathrm{C})$, although in morphospace 2 this distinction was less evident because the species were more compacted along the axis (Fig. 3B). However, the axis also separated species based on other morphological characteristics, such as the relation between head and body size (species with larger heads in relation to body size presenting negative values and species with smaller heads showing positive values) and the number and position of pelvic and dorsal fins. Morphospaces 1 and 3 were characterized by the isolation of the anglerfish (Lophius piscatorius, Lophiiformes), having a transformed first ray of the first dorsal. Moreover, nektonic (Seriola dumerili, Carangidae) and epibenthic (Mullus surmuletus, Mullidae) species with two dorsal fins were located slightly separated along the second axis compared with species with one dorsal fin (Diplodus vulgaris, Sparidae, or Scorpaena porcus, Scorpaenidae) (Fig. 3A and 3C). However, benthic species with specially adapted pectoral fins, such as Trigla lucerna, were isolated and clearly identified in mor- phospace 3 (Fig. 3C). Moreover, in morphospace 2 only Conger conger (Anguilliformes) showed an extreme distribution because of its specially elongated shape, as was also shown in all of the morphospaces, whereas all remaining species were concentrated between -0.1 and 0.1 values, confirming a greater compaction along the axis (Fig. 3B).

\section{Accounting for the observed morphological variation}

The SOV showed no differences among morphospaces, reaching similar values of variance (0.021) in the three cases. By contrast, the QSOR revealed greater disparity, attaining the highest value $(0.028)$ in morphospace 2, which demonstrated a more dispersed distribution of points compared with the remaining morphospaces. Although morphospaces 1 and 3 yielded similar values $(0.011$ and 0.015 , respectively), the lowest filled area in morphospace 1 denoted a more compacted distribution of points located in the two middle quartiles than morphospace 3. 
The VMR yielded values of $8.83,6.64$ and 7.8 for morphospaces 1, 2 and 3, respectively, corresponding with clustered distributions in all cases (K-S test $=0.4031, \mathrm{P}=0.2267 ; \mathrm{K}-\mathrm{S}$ test $=0.4031, \mathrm{P}=0.2267$; $\mathrm{K}-\mathrm{S}$ test $=0.4308, \mathrm{P}=0.2267$, respectively). The kernel analysis evidenced an area of high density in the three morphospaces (red-orange zone; Fig. 4A), which was formed by 12, 12 and 9 species in morphospaces 1 , 2 and 3, respectively. Morphospace 2 displayed several medium-density zones separated from each other, whereas in morphospaces 1 and 3 the species were distributed more closely distributed among them, especially near the centroid, forming a main core zone and favouring the connection between lesser densities (Fig. 4A).

The Clark-Evans approach also denoted a clustered distribution of species in morphospace $1(\mathrm{Z}=-3.6158$, $\mathrm{P}<0.05, \mathrm{r}=0.7)$, morphospace $2(\mathrm{Z}=-3.0809, \mathrm{P}<0.05$, $\mathrm{r}=0.743)$ and morphospace $3(\mathrm{Z}=-3.6312, \mathrm{P}<0.05$, $\mathrm{r}=0.6996)$. The Ripley's function values were higher than those corresponding to spatial randomness, thus confirming the presence of clusters in the three morphospaces (Fig. 4B). The Gabriel graphs displayed two similar clusters of species in the three morphospaces (Fig. 4C). First, a limited number of flatfishes formed $A_{i}$ clusters. Second, a noticeable packing of similar species (sparids, serranids, pomacentrids, haemulids, mullids and scorpaenids) configured the $B_{i}$ clusters, showing a lesser distance and triangulation of points in morphospace 2 than in the remaining morphospaces. Finally, in morphospace 2, a third species packing was observed $\left(C_{2}\right.$ cluster), formed exclusively by species similar to $B_{i}$ clusters but with two dorsal fins, whereas morphospace 3 was similar to morphospace 1 and showed no $C$ clusters.

\section{DISCUSSION}

Landmark-based methods considering only overall body shape have often been used in studies analysing intraspecific or interspecific differences between taxonomically close species (Loy et al. 1999, Valentin et al. 2002, Costa and Cataudella 2007), showing that such variability is related to their ecological features (Loy et al. 2001, Rüber and Adams 2001). In local assemblages, the ecological relationships between species play a strong role in determining the morphological adaptations to many life habits (Clabaut et al. 2007, Ricklefs 2012), suggesting that there is a strong link between ecology and morphology of fish species (Douglas and Matthews 1992, Willis et al. 2005, Cooper and Westneat 2009). Feeding preference is the main ecological factor influencing morphospace structuring, differentiating strict herbivores with small heads, omnivores with taller bodies and shorter caudal peduncles and predators with longer bodies adapted to swimming and larger heads and mouths (Cavalcanti et al. 1999, Kassam et al. 2003, Costa and Cataudella 2007). However, body shape is also affected by habitat: rounded-shaped species are adapted to low activity, living in generalist habits, whereas elongated-shaped species swim in the water column
(Clabaut et al. 2007, Farré et al. 2015). In fact, fishes with flattened or elongated shapes (eels or flatfishes) are usually located at the periphery of morphospaces (Friedman 2010, Tuset et al. 2014, present study).

Although more studies should be performed on other fish communities to confirm these statements at a more general level, our results indicate that the use of specific landmarks and semilandmarks related to fins and external sensorial organs helps to clarify the differentiation between species because it provides more detailed and accurate morphological information on the species, which translates into differences in the species distribution within the morphospace structure. However, due to the lack of similar comparative studies of different landmark schemes, it is necessary to test this methodology in communities with different ecological characteristics to confirm the results of the present study. The most noticeable difference between morphospace 1 and 3 was related to fishes with special morphological structures. The isolated location of Trigla lucerna in morphospace 3 reinforces this assertion, as it presents an extremely extended pectoral fin with the first three rays transformed, involved in locomotion, substrate lodging or feeding strategies (Jamon et al. 2007). Moreover, fishes with presence of sensorial chin barbels used for stimuli reception and finding of food items (Lombarte and Aguirre 1997, Hutchings and Griffiths 2005), such as Mullus spp. and Umbrina spp., were also slightly separated from the main group of Perciformes in relation to the morphospace. It is important to highlight the use of fin shape and sensorial organs (morphospace 3) for analysing the morphological structure of fish assemblages because these anatomical characteristics are common to many species. For example, needlefishes use their characteristic compact set of fins to alter the flows created by body movement, a defining feature of their locomotion strategy (Liao 2002); in burrowing eels, the caudal fin is intimately related to their digging ability (De Schepper et al. 2007); whereas in pelagic eels the presence of a continuous fin resulting from the confluence of dorsal, caudal and anal fins improves swimming performance (Tytell and Lauder 2004); or flying fishes, which possess extremely long pectoral fins that enable gliding flights out of the water after self-propelled jumps to escape predators or to save locomotion costs (Davenport 1994). In addition, benthic species in contact with the substratum, such as frogfishes or many scorpionfishes, use synchronized movements of pectoral and pelvic fins to move over the substrate or to maintain static positions in defensive, alert or rest behaviours (Gosline 1994, Yamanoue et al. 2010), or transformations of pelvic fins into suction discs that help to the adherence on the substrate occurs in gobies (Schoenfuss and Blob 2003). The reduction or modification of pelvic fins used during aggressive or courtship behaviours are also common in balistoids (Yamanoue et al. 2010), as well as the occurrence of spines in pelvic, dorsal and median fins for defence and propulsion purposes in gasterosteids and scorpionfishes (Gosline 1994). By contrast, the identification of species by including the 
position of fins (morphospace 2) clearly influenced the morphospace distribution. In this case, although many species were located in a similar position in morphospaces 1 and 3, the variation in the number of dorsal fins conditioned the results. As this biological character is very important in taxonomy, phylogeny and evolution (Nelson 2006), it suggests that species distribution within morphospace 2 is not sufficient for a full ecological understanding.

The combination of different methods is the best approach for analysing the species occupation within morphospace (Perry et al. 2006, Van Bocxlaer and Schultheiß 2010). Depending on the aims of the study, all the methods have advantages and drawbacks, as discussed above, so an ensemble of different analyses is necessary to corroborate and complement outcomes and obtain a better understanding of the point patterns, thus avoiding the bias that may result from a specific chosen analysis (Wiegand and Moloney 2004, Perry et al. 2006). Although numerical methods are needed to test the statistical significance of outcomes, they are restricted to interactions between points at short scales and can omit relationships at larger distances. Graphical methods are recommended at larger scales because they provide a better and more intuitive visual interpretation of morphospace shape (e.g. Perry et al. 2006, Werdelin and Lewis 2013, Tuset et al. 2014). In this study, the indices of morphological disparity did not provide enough information regarding the spatial distribution of species within morphospaces. The variance of the different axes changes among morphospaces, but their cumulative contribution can express similar total variability even if the morphospaces possess different configurations (Foote 1997, Ciampaglio et al. 2001, Korn et al. 2013), as also shown in our results. Although calculating the areas occupied by points helps to analyse the distribution pattern of points, the measure does not permit the establishment of the specific location and occupation of these points within the morphospace. Therefore, these measurements fail in terms of estimating the distribution and occupation of morphospaces; it is better to use quadrant and nearestneighbour analyses for these purposes (Shen et al. 2008, Ricklefs 2012, Tuset et al. 2014).

Kernel density graphics represented a visual image of species distribution within morphospace and species density in a fixed area, which was a useful tool for delimiting the range of species and quantifying their occurrence probability in space (Silverman 1986, Worton 1989, Fortin et al. 2005). The results showed slight differences between morphospaces, especially between 1 and 3 , focusing mainly on the area shape of higher density (red colour in Fig. 4A). However, in morphospace 3 , this area was arranged in a more elongated and straightened way than in morphospaces 1 and 2 due to species disaggregation favoured by the presence of landmarks defining the presence of chin barbels and a better differentiation of swimming species. However, this graphical representation is unable to establish the connections between close species and organize them in local clusters (Shen et al. 2008, Werdelin and Lewis 2013).
The variance-to-mean ratio and Ripley's function determined a clustered distribution in the three morphospaces, but it cannot display the location of local clusters, thus limiting the perception of morphospace structure. In this context, the Gabriel graph allowed to identify the packing species based on the distances and connections between them. The Gabriel method likely provides a more complex graphical representation to be considered as an extension of the Euclidean minimum spanning tree, the relative neighbourhood graph, and the nearest-neighbour graph (Gabriel and Sokal 1969). Evidently, the selection of the clusters of species within the graph is partially subjective, but ecologically it is very interesting because graphs are able to describe important ecological characteristics of communities, such as structural complexity or relationships between species (Strogatz 2001, Dale and Fortin 2010), where species that are close together interact in the same environment and exploit similar resources. Thus, the packing of species can provide useful information about the internal dynamics within communities. Hence, we propose that natural directions for future research should include this topic in order to test the usefulness and abilities of this graphical method in the study of structural complexity of communities.

In conclusion, the results of this study suggest that depending on the purposes, several methods of landmark selection are able to display the distribution of species within morphospace (Adams et al. 2013). However, including the maximum number of anatomical traits of species, especially those with special morphological adaptations, such as Stomiiformes, Lophiiformes, Ipnopidae (Aulopiformes), etc. (Tuset et al. 2014, Farré et al. 2015), can be important in order to better differentiate the species and characterize them ecologically, as our results demonstrate. Therefore, in analysis of fish communities where species of special morphologies may be present, the method considering fin shape and sensorial organs in the landmark configuration provides an appropriate and accurate description of the spatial occupancy of species, helping to improve the understanding of the structural complexity and ecological processes of fish assemblages. Moreover, although graphical methods are in general more intuitive and interpretable, a combination of different analytical methods, including numerical and graphical ones, is the best and most complete option for assessing the internal occupation of morphospaces.

\section{ACKNOWLEDGEMENTS}

Data of this study were financed by the projects "ESCAL 1" (Ref. PCC30004/99) and "ESCAL 2" (Ref. 02P30015) of the Directorate General of Fisheries of the Government of Catalonia, and "CONFLICT" (Ref. CGL2008-00047) of the Spanish National Research Council. Marc Farré Foix acknowledges a pre-doctoral grant and a third cycle tuition fee grant from the Government of Andorra, ATC-010-AND and AMTC010-AND/2013, academic years 2013-2014 and 2014-2015. 


\section{REFERENCES}

Adams D.C., Rohlf F.J., Slice D.E. 2013. A field comes of age: geometric morphometrics in the 21 st century. Hystrix It. J. Mamm. 24: 7-14.

Anderson R.M., Gordon D.M., Crawley M.J., et al. 1982. Variability in the abundance of animal and plant species. Nature 296: 245-248. http://dx.doi.org/10.1038/296245a0

Angeles A.D.J., Gorospe J.G., Torres M.A.J., et al. 2014. Lengthweight relationship, body shape variation and asymmetry in body morphology of Siganus guttatus from selected areas in five Mindanao bays. Int. J. Aqu. Sci. 5: 40-57.

Azzurro E., Tuset V.M., Lombarte A., et al. 2014. External morphology explains the success of biological invasions. Ecol. Lett. 17: $1455-1463$ http://dx.doi.org/10.1111/ele.12351

Bellwood D.R., Wainwright P.C., Fulton C.J., et al. 2006. Functional versatility supports coral reef biodiversity. Proc. R. Soc. B 273: 101-107. http://dx.doi.org/10.1098/rspb.2005.3276

Bookstein F.L. 1991. Morphometric Tools for Landmark Data. Geometry and Biology. Cambridge University Press, New York.

Cadrin S.X. 2000. Advances in morphometric identification of fishery stocks. Rev. Fish Biol. Fish. 10: 91-112. http://dx.doi.org/10.1023/A:1008939104413

Cavalcanti M.J., Monteiro L.R., Lopes P.R.D. 1999. Landmarkbased morphometric analysis in selected species of serranid fishes (Perciformes: Teleostei). Zool. Stud. 38: 287-294.

Chakrabarty P. 2005. Testing conjectures about morphological diversity in cichlids of lakes Malawi and Tanganyika. Copeia 2005: 359-373. http://dx.doi.org/10.1643/CG-04-089R2

Ciampaglio C.N., Kemp M., McShea D.W. 2001. Detecting changes in morphospace occupation patterns in the fossil record: characterization and analysis of measures of disparity. Paleobiology 27: 695-715.

http://dx.doi.org/10.1666/0094-8373(2001)027<0695:DCIMO $\mathrm{P}>2.0 . \mathrm{CO} ; 2$

Clabaut C., Bunje P.M.E., Salzburger W., et al. 2007. Geometric morphometric analyses provide evidence for the adaptative character of the Tanganyikan cichlid fish radiations. Evolution 61: 560-578.

http://dx.doi.org/10.1111/j.1558-5646.2007.00045.x

Clark P.J., Evans F.C. 1954. Distance to nearest neighbor as a measure of spatial relationships in populations. Ecology 35: 445-453. http://dx.doi.org/10.2307/1931034

Cooper W.J., Westneat M.W. 2009. Form and function of damselfish skulls: rapid and repeated evolution into a limited number of trophic niches. BMC Evol. Biol. 9: 24. http://dx.doi.org/10.1186/1471-2148-9-24

Cornwell W.K., Schwilk D.W., Ackerly D.D. 2006. A trait-based test for habitat filtering: convex hull volume. Ecology 87: 1465-1471.

http://dx.doi.org/10.1890/0012-9658(2006)87[1465:ATTFHF] 2.0.CO;2

Costa C., Cataudella S. 2007. Relationship between shape and trophic ecology of selected species of Sparids of the Caprolace coastal lagoon (Central Tyrrhenian sea). Environ. Biol. Fish. 78: $115-123$.

http://dx.doi.org/10.1007/s10641-006-9081-9

Dale M.R.T., Fortin M.J. 2010. From graphs to spatial graphs. Annu. Rev. Ecol. Evol. Syst. 41: 21-38.

http://dx.doi.org/10.1146/annurev-ecolsys-102209-144718

Davenport J. 1994. How and why do flying fish fly? Rev. Fish Biol. Fish. 40: 184-214 http://dx.doi.org/10.1007/BF00044128

Davis J.C. 1986. Statistics and data analysis in geology. John Wiley \& Sons, New York.

De Schepper N., De Kegel B., Adriaens D. 2007. Morphological specializations in Heterocongrinae (Anguilliformes: Congridae) related to burrowing and feeding. J. Morphol. 268: 343-356. http://dx.doi.org/10.1002/jmor.10525

Dixon P.M. 2002. Ripley's K function. In: El-Shaarawi A.H., Piergorsch W.W. (eds), Encyclopedia of Environmetrics, vol. 3, John Wiley \& Sons, New York, USA, pp. 1796-1803.

Dornburg A., Sidlauskas B., Santini F., et al. 2011. The influence of an innovative locomotor strategy on the phenotypic diversification of triggerfish (Family: Balistidae). Evolution 65: 1912-1926. http://dx.doi.org/10.1111/j.1558-5646.2011.01275.x

Douglas M.E., Matthews W.J. 1992. Does morphology predict ecology? Hypothesis testing within a freshwater stream fish assemblage. Oikos 65: 213-224. http://dx.doi.org/10.2307/3545012

Dryden I.L., Mardia K.V. 1998. Statistical shape analysis. John Wiley \& Sons, New York, 376 pp.

Farré M., Tuset V.M., Maynou F., et al. 2013. Geometric morphology as an alternative for measuring the diversity of fish assemblages. Ecol. Indic. 29: 159-166. http://dx.doi.org/10.1016/j.ecolind.2012.12.005

Farré M., Lombarte A., Recasens L., et al. 2015. Habitat influence in the morphological diversity of coastal fish assemblages. J. Sea Res. 99: 107-117. http://dx.doi.org/10.1016/j.seares.2015.03.002

Foote M. 1997. The evolution of morphological diversity. Annu. Rev. Ecol. Syst. 28: 129-152. http://dx.doi.org/10.1146/annurev.ecolsys.28.1.129

Fortin M.J., Keitt T.H., Maurer B.A., et al. 2005. Species' geographic ranges and distributional limits: pattern analysis and statistical issues. Oikos 108: 7-17. http://dx.doi.org/10.1111/j.0030-1299.2005.13146.x

Friedman M. 2010. Explosive morphological diversification of spiny-finned teleost fishes in the aftermath of the end-Cretaceous extinction. Proc. R. Soc. B 277: 1675-1683. http://dx.doi.org/10.1098/rspb.2009.2177

Gabriel K.R., Sokal R.R. 1969. A new statistical approach to geographic variation analysis. Syst. Biol. 18: 259-278. http://dx.doi.org/10.2307/2412323

Gatz Jr. A.J. 1979. Community organization in fishes as indicated by morphological features. Ecology 60: 711-718 http://dx.doi.org/10.2307/1936608

Gosline W.A. 1994. Function and structure in the paired fins of scorpaenifom fishes. Environ. Biol. Fish. 40: 219-226. http://dx.doi.org/10.1007/BF00002508

Hutchings K., Griffiths M.H. 2005. Identity and distribution of southern African sciaenid fish species of the genus Umbrina. Afr. J. Mar. Sci. 27: 1-21. http://dx.doi.org/10.2989/18142320509504064

Jamon M., Renous S., Gasc J.P., et al. 2007. Evidence of force exchanges during the six-legged walking of the bottom-dwelling fish, Chelidonichthys lucerna. J. Exp. Zool. 307A: 542-547. http://dx.doi.org/10.1002/jez.401

Kassam D.D., Adams D.C., Ambali A.J.D., et al. 2003. Body shape variation in relation to resource partitioning within cichlid trophic guilds coexisting along the rocky shore of Lake Malawi. Anim. Biol. 53: 59-70. http://dx.doi.org/10.1163/157075603769682585

Kasumyan A.O. 2011. Tactile reception and behavior of fish. J. Ichthyol. 51: 1035-1103. http://dx.doi.org/10.1134/S003294521111004X

Klingenberg C.P. 2010. Evolution and development of shape: integrating quantitative approaches. Nat. Rev. Genet. 11: 623-635. http://dx.doi.org/10.1038/nrg2829

Klingenberg C.P., Ekau W. 1996. A combined morphometric and phylogenetic analysis of an ecomorphological trend: pelagization in Antarctic fishes (Perciformes: Nototheniidae). Biol. J. Linn. Soc. 59: 143-177. http://dx.doi.org/10.1111/j.1095-8312.1996.tb01459.x

Korn D., Hopkins M.J., Walton S.A. 2013. Extinction space - A method for the quantification and classification of changes in morphospace across extinction boundaries. Evolution 67: 2795-2810. http://dx.doi.org/10.1111/evo.12162

Laurenson C.H., Hudson I.R., Jones D.O.B., et al. 2004. Deep water observations of Lophius piscatorius in the north-eastern Atlantic Ocean by means of a remotely operated vehicle. J. Fish Biol. 65: $947-960$ http://dx.doi.org/10.1111/j.0022-1112.2004.00496.x

Layman C.A., Langerhans R.B., Winemiller K.O. 2005. Body size, not other morphological traits, characterizes cascading effects in fish assemblage composition following commercial netting. Can. J. Fish. Aquat. Sci. 62: 2802-2810. http://dx.doi.org/10.1139/f05-183

Liao J.C. 2002. Swimming in needlefish (Belonidae): anguilliform locomotion with fins. J. Exp. Biol. 205: 2875-2884.

Lombarte A., Aguirre H. 1997. Quantitative differences in the chemoreceptor systems in the barbels of two species of Mullidae (Mullus surmuletus and M. barbatus) with different bottom habitats. Mar. Ecol. Prog. Ser. 150: 57-64. 
http://dx.doi.org/10.3354/meps 150057

Lombarte A., Gordoa A., Whitfield A.K., et al. 2012. Ecomorphological analysis as a complementary tool to detect changes in fish communities following major perturbations in two South African estuarine systems. Environ. Biol. Fish. 94: 601-614. http://dx.doi.org/10.1007/s10641-011-9966-0

Loy A., Boglione C., Cataudella S. 1999. Geometric morphometrics and morpho-anatomy: a combined tool in the study of seabream (Sparus aurata, Sparidae) shape. J. Appl. Ichthyol. 15: 104-110. http://dx.doi.org/10.1046/j.1439-0426.1999.00116.x

Loy A., Bertelletti M., Costa C., et al. 2001. Shape changes and growth trajectories in the early stages of three species of the genus Diplodus (Perciformes, Sparidae). J. Morphol. 250: 24-33. http://dx.doi.org/10.1002/jmor.1056

McClain C.R., Johnson N.A., Rex M.A. 2004. Morphological disparity as a biodiversity metric in lower bathyal and abyssal gastropod assemblages. Evolution 58: 338-348. http://dx.doi.org/10.1554/03-237

Mercader L., Lloris D., Rucabado J.A. 2001. Tots els peixos del mar Català: Diagnosis i claus d'identificació. Institut d'Estudis Catalans, Barcelona.

Nelson J.S. 2006. Fishes of the World, 4rth edition. Wiley and Sons, New Jersey.

Perry G.L.W., Miller B.P., Enright N.J. 2006. A comparison of methods for the statistical analysis of spatial point patterns in plant ecology. Plant Ecol. 187: 59-82. http://dx.doi.org/10.1007/s11258-006-9133-4

Pie M.R., Traniello J.F.A. 2007. Morphological evolution in a hyperdiverse clade: the ant genus Pheidole. J. Zool. 271: 99-109. http://dx.doi.org/10.1111/j.1469-7998.2006.00239.x

Recasens L., Lombarte A., Sánchez P. 2006. Teleostean fish composition and structure of an artificial reef and a natural rocky area in Catalonia (North Western Mediterranean). Bull. Mar. Sci. 78: 71-82.

Ricklefs R.E. 2012. Species richness and morphological diversity of passerine birds. Proc. Natl. Acad. Sci. USA 109: 14482-14487. http://dx.doi.org/10.1073/pnas.1212079109

Ripley B.D. 1979. Tests of 'randomness' for spatial point patterns. J. Roy. Stat. Soc. B 41: 368-374.

Rohlf F.J. 2003a. TpsDig Version 2.16. Department of Ecology and Evolution, State University of New York at Stony Brook, New York.

Rohlf F.J. 2003b. TpsSmall Version 1.28. Department of Ecology and Evolution, State University of New York at Stony Brook, New York.

Rohlf F.J. 2003c. TpsRelw Version 1.49. Department of Ecology and Evolution, State University of New York at Stony Brook, New York.

Rohlf F.J., Marcus L.F. 1993. A Revolution in Morphometrics. Trends Ecol. Evol. 8: 129-132. http://dx.doi.org/10.1016/0169-5347(93)90024-J

Rüber L., Adams D.C. 2001. Evolutionary convergence of body shape and trophic morphology in cichlids from Lake Tanganyika. J. Evol. Biol. 14: 325-332. http://dx.doi.org/10.1046/j.1420-9101.2001.00269.x

Russell E.S. 1916. Form and function: a contribution to the history of animal morphology. American edition. EP Dutton and Co., New York. http://dx.doi.org/10.5962/bhl.title.3747

Schoenfuss H.L., Blob R.W. 2003. Kinematics of waterfall climbing in Hawaiian freshwater fishes (Gobiidae): vertical propulsion at the aquatic-terrestrial interface. J. Zool. 261: 191-205. http://dx.doi.org/10.1017/S0952836903004102

Shen B., Dong L., Xiao S., et al. 2008. The Avalon explosion: evolution of Ediacara morphospace. Science 319: 81-84. http://dx.doi.org/10.1126/science.1150279

Silverman B.W. 1986. Density estimation for statistics and data analysis. Monographs on Statistics and Applied Probability, Chapman and Hall, London. http://dx.doi.org/10.1007/978-1-4899-3324-9

Smith U.E., Hendricks J.R. 2013. Geometric morphometric character suites as phylogenetic data: extracting phylogenetic signal from gastropod shells. Syst. Biol. 62: 366-385. http://dx.doi.org/10.1093/sysbio/syt002

Strauss R.E., Bookstein F.L. 1982. The truss: body form reconstructions in morphometrics. Syst. Biol. 31: 113-135. http://dx.doi.org/10.1093/sysbio/31.2.113

Strogatz S.H. 2001. Exploring complex networks. Nature 410: 268-276.

http://dx.doi.org/10.1038/35065725
Thompson D.W. 1915. Morphology and mathematics. T. Roy. Soc. Edin. 50: 857-895. http://dx.doi.org/10.1017/S0080456800017105

Tuset V.M., Farré M., Lombarte A., et al. 2014. A comparative study of morphospace occupation of mesopelagic fish assemblages from the Canary Islands (North-eastern Atlantic). Ichthyol. Res. 61: 152-158. http://dx.doi.org/10.1007/s10228-014-0390-2

Tytell E.D., Lauder G.V. 2004. The hydrodynamics of eel swimming I. Wake structure. J. Exp. Biol. 207: 1825-1841. http://dx.doi.org/10.1242/jeb.00968

Valentin A., Sévigny J.M., Chanut J.P. 2002. Geometric morphometrics reveals body shape differences between sympatric redfish Sebastes mentella, Sebastes fasciatus and their hybrids in the Gulf of St Lawrence. J. Fish. Biol. 60: 857-875. http://dx.doi.org/10.1111/j.1095-8649.2002.tb02414.x

Van Bocxlaer B., Schultheiß R. 2010. Comparison of morphometric techniques for shapes with few homologous landmarks based on machine-learning approaches to biological discrimination. Paleobiology 36: 497-515. http://dx.doi.org/10.1666/08068.1

Vergara-Solana F.J., García-Rodriguez F.J., Tavera J.J., et al. 2014. Molecular and morphometric systematics of Diapterus (Perciformes, Gerreidae). Zool. Scripta 43: 338-350. http://dx.doi.org/10.1111/zsc.12054

Villéger S., Ramos Miranda J., Flores Hernandez D., et al. 2010. Contrasting changes in taxonomic and functional diversity of tropical fish communities after habitat degradation. Ecol. Appl. 20: $1512-1522$.

http://dx.doi.org/10.1890/09-1310.1

Wainwright P.C., Belwood D.R., Westneat M.W. 2002. Ecomorphology of locomotion in labrid fishes. Environ. Biol. Fish. 65: 47-62. http://dx.doi.org/10.1023/A:1019671131001

Walker J.A. 2010. An integrative model of evolutionary covariance: a symposium on body shape in fishes. Integr. Comp. Biol. 50: 1051-1056. http://dx.doi.org/10.1093/icb/icq014

Werdelin L., Lewis M.E. 2013. Temporal change in functional richness and evenness in the Eastern African Plio-Pleistocene carnivoran guild. PLoS ONE 8: e57944. http://dx.doi.org/10.1371/journal.pone.0057944

Wiegand T., Moloney K.A. 2004. Rings, circles, and null-models for point pattern analysis in ecology. Oikos 104: 209-229. http://dx.doi.org/10.1111/j.0030-1299.2004.12497.x

Willis S.C., Winemiller K.O., Lopez-Fernandez H. 2005. Habitat structural complexity and morphological diversity of fish assemblages in a Neotropical floodplain river. Oecologia 142: 284-295. http://dx.doi.org/10.1007/s00442-004-1723-z

Wills M.A. 2001. Morphological disparity: a primer. In: Adrain J.M., Edgecombe G.D., Lieberman B.S. (eds), Fossils, phylogeny, and form: an analytical approach. Kluwer Academic/ Plenum Publishers, New York. pp 55-144. http://dx.doi.org/10.1007/978-1-4615-0571-6_4

Winemiller K.O. 1991. Ecomorphological diversification in lowland fresh-water fish assemblages from five biotic regions. Ecol. Monogr. 61: 343-365. http://dx.doi.org/10.2307/2937046

Worton B.J. 1989. Kernel methods for estimating the utilization distribution in home-range studies. Ecology 70: 164-168. http://dx.doi.org/10.2307/1938423

Yamanoue Y., Setiamarga D.H.E., Matsuura K. 2010. Pelvic fins in teleosts: structure, function and evolution. J. Fish. Biol. 77: 1173-1208. http://dx.doi.org/10.1111/j.1095-8649.2010.02674.x

Young K.A., Snoeks J., Seehausen O. 2009. Morphological diversity and the roles of contingency, chance and determinism in African cichlid radiations. PLoS ONE 4: e4740. http://dx.doi.org/10.1371/journal.pone.0004740

Zelditch M.L., Swidersky D.L., Sheeds H.D., et al. 2004. Geometric morphometrics for biologists: a primer. Elsevier Academic Press, London.

Zuanon J., Bockmann F.A., Sazima I. 2006. A remarkable sanddwelling fish assemblage from central Amazonia, with comments on the evolution of psammophily in South American freshwater fishes. Neotrop. Ichthyol. 4: 107-118. http://dx.doi.org/10.1590/S1679-62252006000100012 